\title{
El cuerpo humano y la salud en libros de texto de Educación Primaria (6-11 años), ¿qué aportan al problema socio-científico sobre la lactancia materna como parte de la alimentación en la primera infancia?
}

\author{
Illescas-Navarro, $\mathbf{M}$. \\ Departamento de Didáctica de las Ciencias Experimentales y Sociales, Universidad de Sevilla. España. \\ millescas@us.es \\ ORCID: bttp:/ / orcid.org/0000-0002-4787-2274 \\ Criado, A.M. \\ Departamento de Didáctica de las Ciencias Experimentales y Sociales, Universidad de Sevilla. España. \\ acriado@us.es \\ ORCID: http:/ / orcid.org/0000-0002-6224-9253 \\ Cruz-Guzmán, $\mathbf{M}$. \\ Departamento de Didáctica de las Ciencias Experimentales y Sociales, Universidad de Sevilla. España. \\ mcruagurman@us.es \\ ORCID: http:/ / orcid.org/0000-0003-0018-3620
}

[Recibido: 29 Mayo 2019. Revisado: 31 Agosto 2019. Aceptado: 18 Septiembre 2019]

\begin{abstract}
Resumen: En el presente trabajo se hace un estudio de la forma en la que se presentan en los libros de texto españoles de Educación Primaria los contenidos relativos a la alimentación en la primera infancia (API), y a la lactancia materna (LM). Bajo la hipótesis de que los contenidos tratados serían escasos o bien introducirían concepciones alternativas, la intención es i) determinar la presencia de estos contenidos relativos a la salud y a los mamíferos, asociados a los bloques 2 y 3 del currículo (salud y seres vivos); ii) detectar la presencia de contenidos que promuevan la generación o mantenimiento de concepciones alternativas sobre la LM como API. Pretendemos, de esta forma, contribuir a la investigación en la Didáctica de las ciencias con un trabajo sobre un ámbito poco estudiado, a pesar de su relevancia. Los resultados arrojan una escasa presencia de contenido escolar deseable de ese tema, así como una elevada representación de imágenes que aportan información similar a las concepciones alternativas existentes en el conocimiento cotidiano. De esta forma, los textos analizados pueden contribuir a la ausencia de aprendizaje y a la promoción de conocimiento no deseable en relación a los contenidos sobre alimentación infantil.
\end{abstract}

Palabras clave: Alimentación infantil; Lactancia materna; Educación Primaria; Libros de texto; Educación para la salud.

The human being and the health in the Spanish Primary textbooks (6-11 years old). What do they provide to the socio-scientific problem of the nutrition in the early childhood?

Abstract: This paper studies the presence of contents related to early infant feeding (API), breastfeeding (LM), in Primary Education textbooks. Our hypothesis is that we would find limited contents and misconceptions. The aim is i) to establish the presence or absence of contents related to health and mammals, included in the school curriculum: Health and living beings; ii) detect contents promoting or reinforcing misconceptions about API. Our purpose is to contribute with this research to a field that has been little explored in Science Education, despite its relevance. Actually, we have found a limited presence of proper school contents and, furthermore, a large amount of images containing misconceptions. So we have concluded that this analysed textbooks could promote the absence of learning and the misconceptions related to the early infant feeding.

Keywords: Early infant feeding; Breastfeeding; Primary Education; Textbook content; Health education. 
Para citar este artículo: Illescas-Navarro M., Criado, A. M., Cruz-Guzmán, M. (2020) El cuerpo humano y la salud en libros de texto de Educación Primaria (6-11 años), ¿qué aportan al problema socio-científico sobre la lactancia materna como parte de la alimentación en la primera infancia?. Revista Eureka sobre Enseñanza y Divulgación de las Ciencias 17(1), 1302. doi: 10.25267/Rev_Eureka_ensen_divulg_cienc.2020.v17.i1.1302

\section{Introducción}

Hemos observado que ha surgido en nuestra sociedad un aparente dilema en cuanto a la forma de alimentación en la primera infancia (API). Al utilizar API nos centramos en la etapa de la vida en la que el ser humano es lactante. Y la opción consustancial con el hecho de ser mamíferos sería la alimentación mediante lactancia materna. En los medios de comunicación se pueden encontrar ejemplos de que se está planteando el tema como un enfrentamiento entre los que están a favor de la lactancia materna (LM) y los que defienden la alimentación con leche artificial (De Vega 2018). Sin embargo, esta situación no es sencillamente dicotómica y responde a una brecha informativa entre el conocimiento científico en este campo y el conocimiento cotidiano, asociado a concepciones alternativas, que tiene la población, incluida una buena parte de los profesionales de la salud (Pallás y Baeza 2006). Consideramos que la educación, y la enseñanza de las ciencias en particular, es un espacio oportuno para aportar información que pueda orientar las decisiones referidas a las actitudes de la población hacia la alimentación de los lactantes. Y de esta forma dar a conocer las situaciones (la mayoría) en las que se puede iniciar y continuar con éxito la API con LM, así como las razones y las ocasiones en las que es posible y necesario alimentar a los bebés con preparados de fórmula artificial.

Nos encontramos, pues, ante un problema socio-científico, ya que algunos ciudadanos se pueden encontrar, en algún momento de su vida, ante la necesidad de tomar decisiones fundamentadas sobre la elección del tipo de API.

Este trabajo forma parte de una investigación más amplia en la que se hace un estudio exploratorio sobre el interés y conocimientos de los futuros maestros acerca de la temática de la API y en particular de la LM, como un problema socio-científico relevante, que podría ser interesante abordar en la formación de maestros, ya que su inclusión como contenido escolar es pertinente al asociarlo con las funciones de relación y nutrición de la especie humana como mamífero. De hecho, está recomendado y hay evidencias de la necesidad de formación de los docentes sobre el tema (Cherrett et al., 2012; Clark, Anderson, Adams y Baker 2008; Consejería de Salud 2006; Duncan y Bartle 2014; Martínez-Roche 2000; OMS 2000a, 2000b). Así, surge la necesidad de valorar en qué medida se trata el tema de la API en el material curricular de uso común en Educación Primaria, los libros de texto. De este modo, podríamos llegar a hacer propuestas para que los escolares puedan contar con la información necesaria y formen opiniones fundamentadas.

\section{Fundamentos biológicos de la API saludable}

Existe consenso en el ámbito científico en cuanto a la conveniencia de iniciar la alimentación de las personas con leche materna durante la primera hora de vida (OMS 2009). En lo referente a los efectos protectores de la LM, la alimentación de los lactantes con leche artificial supone una serie de desventajas, ampliamente estudiadas, como las que recopila la exhaustiva revisión de Brahm y Valdés (2017): La LM ha demostrado ser un factor protector contra diversas enfermedades infectocontagiosas, cardiovasculares, obesidad, diabetes, asma y alergias, así como contra la leucemia, enterocolitis necrotizante, enfermedad celíaca y enfermedades inflamatorias intestinales. Asimismo, tiene un impacto positivo en el desarrollo neuronal, mejorando el cociente intelectual y pudiendo tener una disminución del riesgo de otras condiciones como el déficit atencional, trastorno generalizado del desarrollo y 
alteraciones de conducta. La API con LM puede prevenir la mortalidad infantil, ya que disminuye el riesgo de muerte súbita del lactante.

El uso de fórmulas lácteas, además de suponer la pérdida de todos los efectos protectores de la LM, tiene riesgos inherentes asociados para la salud del lactante: aumentando el riesgo de las alteraciones de la cavidad oral y afectando negativamente a la microbiota intestinal, la oxigenación y la termorregulación del lactante. Del mismo modo, está asociada a riesgos para la salud de la madre que no amamanta: elevada incidencia de cáncer de pecho y de ovario, diabetes tipo 2, menor recuperación del peso gestacional, infarto de miocardio y síndrome metabólico (Stuebe 2009).

La relevancia de la API se ha constatado en múltiples estudios científicos. En este sentido, tenemos los informes a nivel internacional de la Organización Mundial de la Salud (OMS 2002, 2011), que recomiendan una alimentación basada en LM exclusiva durante los 6 primeros meses de vida, seguida de la introducción de alimentos complementarios en la dieta y su continuación hasta los 2 años o más. Idea apoyada también por el Comité de Lactancia Materna de la Asociación Española de Pediatría (AEPED), la Academia Americana de Pediatría, la Comisión Europea y la Asociación Española de Pediatría de Atención Primaria, entre otras. Estudios particulares subrayan el amamantamiento como la manera específica para la API en humanos (Aguayo et al. 2008) y se aporta información referente al valor nutricional de la LM (Basulto 2013).

Este panorama descrito nos señala que existe una amplia bibliografía entorno a la API centrada en la LM. A pesar de ello, parece que estos estudios no han conseguido desterrar las falsas creencias que forman parte del conocimiento cotidiano de la población (Martínez 2015; Padró 2017). Como exponen estas autoras, se trata de ideas del tipo de las que se exponen a continuación: 1) equivalencia de las cualidades de la lactancia artificial y la lactancia materna, 2) restricciones en la duración de la alimentación con lactancia materna, 3) disminución de la capacidad nutritiva de la leche materna, según el tiempo transcurrido o el tipo de mujer, 4) asociación de atributos como el volumen del pecho con la capacidad de producción de leche, 5) ignorancia de la capacidad innata de búsqueda y succión de los recién nacidos mamíferos y, por ende, en los bebés.

Por su parte, Angell, Alexander y Hunt (2011) encontraron en su estudio que la mayoría de los escolares no pensaba en la LM para alimentar a un recién nacido y consideraban incluso que podía comer sólidos. Y en la investigación llevada a cabo por Bottaro y Giugliani (2008) los escolares no asociaban el pecho materno con la función de alimentación.

En la misma línea, los conocimientos sobre los nutrientes y función de la leche se desconocen (Rodrigo y Ejeda 2009). En este sentido, se atribuyen efectos como fortalecer los huesos (Martín del Pozo 2013) o favorecer el crecimiento (Banet y Núñez 1991).

El origen histórico de algunas de estas falsas creencias coincide con la revolución industrial en el S.XIX. En las fábricas se contrataba a mujeres con hijos lactantes, que pasaban allí largas jornadas laborales. Se comenzaron a comercializar sucedáneos de leche humana utilizando estrategias publicitarias que contenían mensajes sin base científica. Los anuncios ponían en duda las cualidades nutritivas de la leche materna, así como la capacidad de las madres para amamantar. Por el contrario, se potenciaba la capacidad nutritiva de la leche artificial con el uso de imágenes que mostraban niños sanos y felices, alimentados con leche artificial (Vallone 2009). Por todo ello, varias generaciones de mujeres perciben que la capacidad de su cuerpo para amamantar es ambigua (Paricio et al. 1999).

En 1981 se adoptó un acuerdo en la Asamblea Mundial de la Salud, el Código Internacional de Comercialización de Sucedáneos de Leche Materna. Su objetivo era proteger la API de 
prácticas comerciales poco éticas, promover la LM y dar un uso correcto a la leche artificial, para conseguir una nutrición segura y eficiente para los lactantes. Esta situación está regulada de forma parcial a nivel nacional (BOE 2014a). A pesar de estas regulaciones, la población sigue recibiendo mensajes confusos acerca de la API, conservando concepciones alternativas en este aspecto (Díaz-Méndez 2012).

\section{Papel de la educación en la enseñanza y aprendizaje sobre la API}

Anteriormente se ha hecho referencia a falsas creencias sobre la lactancia y, ante ello, desde el ámbito de la Educación para la salud se aportan argumentos de que los conocimientos sobre API tienen más relevancia de la que se les viene prestando (de Toledo et al. 2007; Fujimori, Morais y França 2008; Hernández-Aguilar, Aguayo y Gómez 2008). Esto es debido a la dualidad de su carácter: biológico y cultural. Lo biológico engloba el instinto y los reflejos del bebé, que son innatos. Mientras que es necesario recibir educación sobre el modo de proceder para alimentar a un lactante, ya que su transmisión es cultural (Becerra, Peña, Fuentes y Rodríguez 2009).

De lo anterior se deriva la necesidad de acciones educativas en este sentido. Tomando un papel importante las políticas sanitarias gubernamentales. En particular, en el Reino Unido se publicó una declaración acerca de la situación de la LM en el país (RCPCH 2017). En el documento se insta a promover acciones que contribuyan a la normalización de la LM como la opción a elegir para la API, a través de recomendaciones dirigidas, entre otros, a las autoridades competentes (gobiernos y entidades de salud pública). Una de ellas es que se familiarice a los ciudadanos con ella desde la escuela. Necesidad ya mencionada por StuartMacadam y Dettwyler (1995), Martínez-Roche (2000), la Consejería de Salud (2006) y la OMS (2000a, 2000b).

Desde el ámbito educativo la idea se refrenda a través de las investigaciones realizadas. En particular, se concluye que es pertinente centrarse en las repercusiones de la alimentación sobre la salud y la higiene en la etapa de Educación Primaria (Banet et al. 2004; Del Carmen 2010; Pérez de Eulate y Llorente 2015). En este sentido, Gómes (2012), en su tesis acerca de la transmisión de la cultura alimentaria, apunta la importancia del papel de la escuela, complementario al de la familia, para abordar los contenidos sobre alimentación, en su vertiente nutricional, de higiene y en relación con la salud. No obstante, en otras investigaciones acerca de la construcción del conocimiento sobre la nutrición humana, no se aborda la API (Rivadulla-López, García-Barros y Martínez-Losada 2016; Rivadulla-López, Fuentes y García-Barros 2017).

Continuando con la dimensión educativa, el currículo de Educación Primaria español (BOE 2014b) presenta la ciencia como instrumento indispensable para comprender el mundo y para desarrollar actitudes responsables y críticas sobre aspectos relacionados con los avances científicos y los seres vivos. Promueve el desarrollo de una actitud de toma de decisiones argumentadas ante los problemas, ayudando a los escolares a valorar las consecuencias, por ejemplo, en la elección del tipo de API. Asimismo promueve contenidos curriculares muy relacionados con la LM como API. A saber, en el bloque 2: fisiología y anatomía, las funciones de relación, nutrición y reproducción, acciones para prevenir enfermedades y contenidos relacionados con la toma de decisiones. En el bloque 3: características y estructura de los seres vivos y su clasificación, entre otros. Sin embargo, el hecho de que la API no aparezca específicamente como contenido curricular puede haber originado que no se encuentren precedentes, en la literatura del área de Didáctica de las Ciencias, sobre esta temática. Aun así, los propios maestros en formación lo consideran oportuno y lo relacionan con los dos bloques del currículo mencionados (Illescas-Navarro, Cruz-Guzmán y Criado 2018). 
En lo relativo a intervenciones a nivel escolar, desde el ámbito sanitario se aportan argumentos de la importancia de las mismas para modificar los conocimientos, actitudes y normas sociales en los niños respecto a LM como API (Jiménez-Moya 2016). Existen acciones educativas y proyectos, en el contexto nacional e internacional, encaminados a acercar a las escuelas la LM como forma de API. Y se ha comprobado que favorecen la autopercepción de los escolares como mamíferos y aumentan sus conocimientos sobre las implicaciones positivas para la salud de la madre y del lactante. También se han constatado efectos positivos en las actitudes, percepciones y conciencia sobre el tema (Bottaro y Giugliani 2009; Costa, DinizSantos, Santana y Silva 2006; Costa y Silva 2008; Fujimori et al. 2008; Gavira-López, GaviraSegovia, Jiménez-López, López-Pérez y Suárez-Bárcena 2013; Jiménez-Moya 2015; LaredoOrtiz 2005; Terrengui 2003; WABA 1999).

Aun cuando las intervenciones puntuales promovidas por profesionales de la salud, antes mencionadas, son efectivas, la información sobre la forma de API más saludable no llega a ser asimilada por la población. Y cuando se investiga el ámbito escolar se encuentra que muchos maestros están poco preparados y no cuentan con recursos para apoyar la LM como modo de API (Duncan y Bartle 2014). En este aspecto, en sondeos con maestros en ejercicio, estos reconocen que los libros de texto no ayudan mucho a trasladar el curriculum al aula, sobre todo a nivel competencial (Rodríguez-Moreno; de Pro-Bueno y Molina-Jaén 2018).

\section{Antecedentes del estudio de la API en los libros de texto}

A pesar de la tendencia a la innovación educativa, los libros de texto siguen siendo el recurso preferido por estudiantes y profesores como herramienta de apoyo a la docencia y esto determina en gran medida la actividad en las aulas (Azcárate y Serradó 2006; Martins y Brigas 2005; Palacios 2017; Perales y Vílchez 2012). Esta predilección supone un factor limitante, pues se ha constatado que los libros de texto presentan pocas innovaciones y, con frecuencia, contenidos erróneos o inadecuados (Cañal y Criado 2002; Campanario 2003; Palacios-Díaz y Criado 2017).

Acercando el foco hacia el ámbito biológico, en el análisis sobre cómo se abordan los seres vivos en los libros de texto de nuestro país se han detectado ciertas diferencias respecto al tratamiento de los animales, comparados con otros ámbitos. Por ejemplo, se ha descrito la escasez de trabajos prácticos sobre animales (García-Barros y Martínez-Losada 2003). En cambio, abundan las actividades experimentales con plantas (Rodríguez, De las Heras, Romero y Cañal 2014).

Con respecto al tópico que nos ocupa, la búsqueda en la literatura nos ha reportado pocos trabajos en los que se investigue sobre la presencia de contenidos sobre API en manuales de educación. Del Cid y Rivas (1989) ya se preguntaban si en la escuela se respondía a las demandas de la sociedad en relación a la alimentación. Y consideraron insuficiente el tratamiento de su relación con la salud.

Por su parte, Torres (2019) advierte de los efectos de los sesgos en la información que aportan los libros de texto. Por ejemplo, en forma de exclusión: lo que no se ve, no se considera, y alerta de que las imágenes dan información que puede llevar a la adquisición de concepciones alternativas por parte de los escolares, como la ausencia de referencias a las glándulas mamarias en los temas dedicados a la reproducción humana y mamíferos. Este hecho también se ha constatado en material curricular de Educación Secundaria (Hervás 2014). La importancia de las imágenes en los libros de texto también se ha hecho patente en otros estudios (González 2015; Perales 2006).

Pegenaute (2007) realizó un análisis de libros de $3^{\circ}$ a $6^{\circ}$ de Primaria con unidades didácticas referentes a animales, reproducción y nutrición humana en busca de contenidos relacionados 
con la LM. Sus conclusiones son que este tipo de contenidos se tratan en pocos casos, de manera superficial, imprecisa y restringida a algunos temas relacionados con la reproducción humana.

Galvão y Silva (2011) analizaron libros de texto de Conocimiento del Medio para primer ciclo de Educación Básica (8-12 años) de Portugal, en busca de contenidos relacionados con la API. Encontraron un bajo número de alusiones a la naturaleza mamífera del ser humano y varias imágenes que promovían la alimentación artificial, a pesar de que los temas ofrecían oportunidades para ayudar a los escolares a aprender una cultura de la lactancia. Destacan la conveniencia de incluir contenidos sobre LM como primer alimento saludable y aportan sugerencias para hacerlo.

Posteriormente, en Brasil, estudiaron manuales de Enseñanza Primaria (8-12 años) de la asignatura Ciencias. No encontraron referencias explícitas a la LM en humanos, un tercio de los libros contenían la referencia a que los mamíferos maman; una quinta parte informaban sobre la duración de la LM en la API (con referencias a las recomendaciones de la OMS) y una octava parte hacía mención al efecto protector para la salud. Destacan la ausencia de contenidos referentes a la anatomía y fisiología (Galvão y Silva 2013).

Por su parte, Pozuelos, Morcillo y Travé (2016) tratan cómo se aborda la alimentación en los libros de texto y observan que los contenidos están presentados de una forma disciplinar, sin conexión con la vida cotidiana de los estudiantes. Concluyen resaltando la importancia de la implicación familiar y del sector sanitario para complementar y dar coherencia a la educación para una alimentación saludable.

En cuanto al aspecto competencial de la enseñanza sobre alimentación, se ha observado que hay poca presencia de contenidos procedimentales y actitudinales relacionados con la salud ambiental y el desarrollo social, haciéndose hincapié mayoritariamente en los contenidos conceptuales con función informativa (Torres, Marrero, Navarro y Gavidia 2018).

Finalmente, en lo que se refiere al tratamiento de los contenidos relacionados con la reproducción en libros de texto, se observan omisiones, como las referencias a las glándulas mamarias al hablar de caracteres secundarios. Además, se aprecia la presencia de imágenes innecesarias y actividades memorísticas en detrimento de analogías, metáforas y actividades sobre resolución de problemas (Peláez, Rodriguez y Occelli 2010).

Retomando la temática que nos ocupa, percibimos que a la línea sobre educación y API iniciada le queda mucho por desarrollar. No se han actualizado estudios iniciales llevados a cabo hace una década, por ejemplo, comparando lo observado por Pegenaute (2007) en Cataluña con lo que pueda ocurrir en otra comunidad autónoma, o relacionando los estudios de Galvão y Silva $(2011,2013)$ realizados en Portugal y Brasil con la situación que pueda darse en nuestro país. Así mismo, faltaba por verificar si al haber cambiado la ley educativa los libros han cambiado en lo que respecta al tratamiento de la LM. Así, con este estudio pretendemos completar y aportar una actualización a los conocimientos existentes en esta línea. Consideramos que la reproducción, la alimentación y, relacionada con ambas, la API, deberían tratarse de forma exhaustiva y adecuada a cada edad.

\section{Objetivos}

La finalidad principal del trabajo es conocer cómo tratan los libros de texto de Educación Primaria la API, concretamente la LM: ¿en qué medida los contenidos contribuyen a la normalización de la LM como modo específico de API? Esta finalidad general se concreta en responder a las preguntas de investigación que se pueden ver en la tabla 1. 
Tabla 1. Preguntas de investigación

i) ¿Qué información dan los libros de texto sobre la API en relación con la salud del hijo y de la madre?

ii) ¿Existe mención a las funciones vitales y estructuras anatómicas del cuerpo humano relacionadas con la API?

iii) ¿Relacionan los libros de texto a los mamíferos con la LM?

iv) ¿Se indica específicamente que el ser humano pertenece a la clase de los mamíferos?

v) ¿Presentan los libros de texto ideas alejadas del conocimiento escolar deseable que afianzan o transmiten concepciones alternativas sobre la API?

vi) ¿Se observan diferencias entre los manuales editados durante la vigencia de la LOE y los publicados en vigencia de la LOMCE, en relación a las anteriores preguntas de investigación?

\section{Metodología}

\section{Muestra}

Se analizaron 75 libros de Educación Primaria (de los cursos primero a sexto) de 7 de las editoriales más utilizadas en la comunidad andaluza (ver Anexo I). Se trata de una muestra de conveniencia, estudiando las editoriales a las que se ha tenido acceso a través de la biblioteca de la Facultad de Ciencias de la Educación de la Universidad de Sevilla.

Un segundo criterio de selección fue la edición de los mismos de acuerdo con las dos leyes educativas respectivas promulgadas por el gobierno central español, dentro de la década contemplada: 54 de los libros habían sido editados según la legislación anterior, la ley Orgánica de Educación (LOE) y 21 según la actual ley Orgánica de Mejora de la Calidad Educativa (LOMCE). Es digno de mención el hecho de que en la Comunidad autónoma de Andalucía los responsables autonómicos retrasaron todo lo posible la implementación de la última ley por desacuerdo con criterios del gobierno central. Ello provocó que las editoriales se resistieran durante años a publicar textos de acuerdo con la nueva ley hasta que no tuvieran asegurada su venta y utilización.

Se ha de tener en cuenta que en este estudio se han unificado las editoriales que pertenecen al mismo grupo editorial, de tal manera que Santillana y Grazalema, ambas del grupo PRISA, aparecen como Santillana. De forma similar, Luis Vives del Grupo Edelvives, aparece como Edelvives y Guadiel, del grupo EDEBÉ, aparece como Edebé.

\section{Instrumento y proceso de análisis}

Para el análisis de la información se construyó un instrumento de análisis, cuya versión final se consiguió después de mejoras reiterativas, tras estudio bibliográfico y análisis interjueces. En su diseño se partió de la tabla propuesta por Pegenaute (2007). En las siguientes mejoras, la tabla se enriqueció con las aportaciones de Galvão y Silva (2011). De esta manera, después de un proceso de selección y algunas modificaciones, que se describen en las siguientes líneas, se obtuvo un primer instrumento completo (tabla 2) para el análisis de la información de los libros de texto objeto de este estudio. El instrumento fue revisado y avalado por cuatro matronas, además de otras dos investigadoras del área de Didáctica de las ciencias.

Así, el instrumento de análisis utilizado es de tipo descriptivo y está formado por 6 ítems clasificados en 3 bloques de contenidos. Los contenidos registrados se seleccionaron y ajustaron al propósito de la investigación, atendiendo a la homogeneidad, exclusión mutua, pertinencia, objetividad, exhaustividad y productividad. Es decir, se tuvo en cuenta el sentido de las palabras y el análisis de los temas o categorías propuestas. Ello corresponde con la técnica de análisis de contenido a nivel semántico (Gil-García et al. 2002). Se cuidó la correspondencia entre las preguntas de investigación y los ítems, de la siguiente manera: la pregunta $i$ se relaciona con los ítems 1 y 2 , la pregunta $i i$, con los ítems 3 y 4 , las preguntas $i i i \mathrm{y}$ $i v$, con los ítems 5 y 6 respectivamente, y las preguntas $v$ y vi están relacionadas con todos. 
Del mismo modo que en el estudio de Galvão y Silva (2011), se establecieron las categorías a priori y se siguió un método deductivo. Para ello, nos basamos en Pegenaute (2007), que propone una lista de contenidos a evaluar en los textos y sus ítems respectivos surgen de un amplio barrido de los aspectos que considera que los textos deberían atender para contribuir al aprendizaje significativo y anticipándose a posibles concepciones alternativas.

Las categorías se seleccionaron y se reconstruyeron en interacción con los datos y en iteraciones sucesivas. Para construir un instrumento adecuado a este estudio y que abordase nuestras preguntas de investigación, algunos ítems se mantuvieron como los originales: el ítem 6 de nuestro instrumento (equivalente al 1 de Pegenaute y al 1 y 2 de Galvão y Silva) y el ítem 4 (correspondiente al 5 de Pegenaute y al 7 de Galvão y Silva).

Otros se reformularon con el propósito de utilizar una terminología más actualizada. Por ejemplo, nuestro ítem 1 (correspondiente al 4 de Pegenaute y al 6 de Galvão y Silva) incluye modificaciones en la redacción por razones de actualización del lenguaje utilizado en el ámbito sanitario. En este sentido, anteriormente se trataba la LM como la forma óptima de API, en lugar de la normal. Esta idealización de la LM ha sido contraproducente, porque ha reforzado la percepción de que la alimentación con leche de fórmula es la forma estándar de alimentar a los bebés, cuando en realidad conlleva desventajas para la salud (Berry y Grible 2008).

Otras modificaciones se realizan por la necesidad de conseguir una validez de contenido, por ejemplo, para actualizar conceptos y aspectos relativos a concepciones alternativas, así como para adaptarlo a los objetivos de nuestra investigación. Encontramos ejemplos de esto en el ítem 2, correspondiente al ítem 10.4 de Pegenaute y al 12 de Galvão y Silva, modificados para ajustarlos al contenido relativo a nuestra área de conocimiento. Finalmente, el ítem 3 de nuestro instrumento corresponde al ítem 2 de Pegenaute y al 3 de Galvão y Silva, al que cambiamos la expresión «humanos» por "seres vivos», cuando se trata de referirnos a las funciones vitales de estos, y al que hemos subdividido en 3.a. (Nutrición) y 3.b. (Relación).

Asimismo, estuvimos atentos a la aparición de nuevas categorías que pudieran emerger durante el proceso de análisis, hecho que implica también el uso del método inductivo (Porta y Silva 2003). Por ejemplo, el ítem 5 de nuestro instrumento se añade como modificación del ítem 2 de Galvão y Silva, para contar con un ítem referido a mamíferos en general.

En la tabla 2 se han detallado los contenidos que se pueden incluir en la enseñanza de las Ciencias Naturales relacionadas, en la primera columna, con el currículo de Primaria (BOE 2014b). Para el análisis cualitativo se ha desglosado cada ítem en una selección de contenidos cuya presencia se considera deseable, así como algunos contenidos susceptibles de promover o afianzar concepciones alternativas u obstáculos para el aprendizaje sobre la alimentación infantil al inicio de la vida, cuya presencia en libros de texto no sería conveniente.

$\mathrm{El}$ análisis de los textos fue realizado por la primera autora del presente trabajo, en iteraciones sucesivas verificando la presencia de los aspectos señalados, destacando la ausencia de dificultades en la aplicación del instrumento. Se analizaron los manuales, clasificando los contenidos (textual o imagen) de cada libro según su correspondencia con los contenidos del instrumento. Para cada ítem, se registró si el contenido del texto o imagen correspondía a conocimiento escolar deseable o conocimiento no deseable. La misma investigadora volvió sobre los datos dos meses después de la primera vez, con la intención de realizar una validación intrajuez (Padilla 2002). En este segundo caso se ratificó la mayor parte de la clasificación realizada anteriormente. A lo largo del proceso, con el objetivo de asegurar la fiabilidad de la valoración, se consensuaron aspectos dudosos de los resultados con las demás autoras del trabajo resolviendo, por acuerdo, las disparidades encontradas, que no alcanzaron ni el $5 \%$ de las cuestiones. 
Se anotaron datos referentes a la frecuencia de aparición de cada contenido en cada texto, así como el cómputo de esa frecuencia por ejemplar analizado.

Tabla 2. Instrumento de análisis de los libros de texto.

\begin{tabular}{|c|c|c|}
\hline Contenidos & Ítems $/ \mathrm{C}$ & $\mathrm{D}^{1} / \mathrm{C}$ noD ${ }^{2}$ para cada contenido escolar \\
\hline \multirow{6}{*}{$\begin{array}{l}\text { Salud } \\
\text { (Bloque } 2 . \\
\text { El ser } \\
\text { humano y } \\
\text { la salud) }\end{array}$} & Ítem 1 & $\begin{array}{l}\text { Efecto protector de la LM ante problemas de salud. La API con leche artificial } \\
\text { conlleva riesgos. }\end{array}$ \\
\hline & C D & $\begin{array}{l}\text { Beneficios madre-hijo/a: la LM previene enfermedades y problemas de salud } \\
\text { psicológicos. } \\
\text { Composición de la leche, tipos de leche utilizada en API. }\end{array}$ \\
\hline & $\mathrm{C}$ noD & La lactancia artificial es una opción equivalente a la LM para la API. \\
\hline & Ítem 2 & $\begin{array}{l}\text { El periodo de la API: } 6 \text { meses de LM como alimento exclusivo, y hasta que la } \\
\text { madre y/o el lactante deseen. }\end{array}$ \\
\hline & C D & $\begin{array}{l}\text { Leche materna, primer alimento específico: la OMS y la AEPED la recomiendan } \\
\text { hasta los } 6 \text { meses como alimento exclusivo, a partir de entonces, complementada con } \\
\text { otros alimentos hasta los } 2 \text { años o más, si la madre y el hijo/a lo desean. }\end{array}$ \\
\hline & C noD & $\begin{array}{l}\text { La LM como API solo se da a los recién nacidos. } \\
\text { La LM como API solo se da los primeros meses. } \\
\text { La LM como API solo se da mientras los lactantes no tienen dientes. }\end{array}$ \\
\hline \multirow{6}{*}{$\begin{array}{l}\text { Cuerpo } \\
\text { humano } \\
\text { (Bloque } 2 \text {. } \\
\text { El ser } \\
\text { humano y } \\
\text { la salud) }\end{array}$} & Ítem 3 & $\begin{array}{l}\text { La LM como API tiene dos de las tres funciones de los seres vivos: nutrición } \\
\text { (3.a) y relación (3.b). }\end{array}$ \\
\hline & C D & $\begin{array}{l}\text { La LM como API está implicada en la función vital de nutrición. } \\
\text { La LM como API está implicada en la función vital de relación. }\end{array}$ \\
\hline & C noD & $\begin{array}{l}\text { Llega un momento en que la LM ya no nutre. } \\
\text { Hay mujeres cuya leche no nutre. } \\
\text { Función de relación desligada de la API (lactantes que comen solos). }\end{array}$ \\
\hline & Ítem 4 & $\begin{array}{l}\text { Anatomía y fisiología de la } \mathrm{LM} \mathrm{C} \text { Cómo es y cómo funciona una mama humana } \\
\text { para producir leche? }\end{array}$ \\
\hline & C D & $\begin{array}{l}\text { Aparato reproductor: anatomía de la mama humana (estructura y cambios en la } \\
\text { glándula mamaria). } \\
\text { Aparato reproductor: fisiología de la producción de leche (regulación hormonal). }\end{array}$ \\
\hline & $\mathrm{C}$ noD & El tamaño del pecho influye en la producción de leche. \\
\hline \multirow{6}{*}{$\begin{array}{l}\text { Seres } \\
\text { vivos: } \\
\text { Mamíferos } \\
\text { (Bloque 3. } \\
\text { Los seres } \\
\text { vivos) }\end{array}$} & Ítem 5 & Los animales mamíferos maman leche de sus madres tras nacer. \\
\hline & C D & Los animales mamíferos maman de sus madres. \\
\hline & $\mathrm{C}$ noD & Los animales en su hábitat toman leche en biberón. \\
\hline & Ítem 6 & Somos mamíferos, nos alimentamos de las mamas de nuestras madres. \\
\hline & C D & $\begin{array}{l}\text { Los seres humanos somos mamíferos: nos alimentamos de las mamas de nuestras } \\
\text { madres. } \\
\text { Los seres humanos somos mamíferos: las mujeres tienen la capacidad de amamantar. } \\
\text { El recién nacido tiene el instinto de reptar hacia el pecho y agarrarse correctamente } \\
\text { para mamar. } \\
\text { La especie humana es altricial, nace sin terminar su desarrollo, necesita cuidados para } \\
\text { sobrevivir: contacto con la figura primaria de apego y succión nutritiva y afectiva. }\end{array}$ \\
\hline & C noD & Los recién nacidos han de ser enseñados para ser capaces de mamar adecuadamente. \\
\hline
\end{tabular}

${ }^{1} \mathrm{C}$ D. Contenido escolar deseable sobre API; ${ }^{2} \mathrm{C}$ noD. Contenido escolar no deseable sobre API

\section{Resultados}

En el análisis descriptivo cuantitativo, encontramos que los diferentes contenidos aparecen en las frecuencias que se indican en la tabla 3. Comentaremos estos resultados por categorías y en orden decreciente de presencia de contenidos relacionados con la alimentación en la primera infancia. Asimismo, mencionaremos la presencia de contenidos que pueden introducir conocimiento no deseable.

Los valores evidencian que la presencia de los contenidos que se buscaban no es homogénea en el material curricular analizado, hallando escasa representación en la mayor parte de ítems.

Observando la tabla es de destacar que el valor más alto que encontramos se refiere a la 
presencia en los libros de texto del ítem 5 (los mamíferos maman leche de sus madres tras nacer), de tal manera que aparece 82 veces en 43 de los libros de texto como contenido escolar deseable. Además, la variedad de especies domésticas y salvajes es elevada, incluyendo también algunos casos menos comunes, y fuera del patrón prototípico de mamífero, como el ornitorrinco. Es necesario destacar, en dos casos, la presencia de dibujos de tres distintos tipos de animales (aves, mamíferos y peces), señalando algunas de sus partes para diferenciarlos. Sin embargo, en la foto de la vaca (representación de mamífero) no aparecen señaladas las mamas. Pensamos que si el objetivo es enseñar las diferencias entre grupos de animales, se debe hacer hincapié en las características distintivas de cada grupo y la presencia de mamas en mamíferos es un rasgo a destacar a los escolares, cuya tendencia sería fijarse en aspectos perceptivos como que el animal posea el cuerpo cubierto de pelo.

Tabla 3. Frecuencia de aparición de forma correcta o incorrecta de cada ítem en el libro de texto.

\begin{tabular}{|c|c|c|c|c|c|}
\hline \multirow[t]{2}{*}{ Contenidos } & \multirow[t]{2}{*}{ Ítems } & \multicolumn{2}{|c|}{$\begin{array}{c}\text { Presencia } \\
\text { C. Deseable } \\
\end{array}$} & \multicolumn{2}{|c|}{$\begin{array}{c}\text { Presencia } \\
\text { C. no Deseable } \\
\end{array}$} \\
\hline & & N.R. $^{1}$ & N.L. $^{2}$ & N.R. & N.L. \\
\hline \multirow[t]{2}{*}{ Salud } & $\begin{array}{l}\text { 1. Efecto protector de la LM ante problemas de salud. La } \\
\text { API con leche artificial conlleva riesgos }\end{array}$ & 0 & 0 & 20 & 18 \\
\hline & $\begin{array}{l}\text { 2. El periodo de la API: } 6 \text { meses de LM como alimento } \\
\text { exclusivo, y hasta que la madre y/o el lactante deseen }\end{array}$ & 1 & 1 & 10 & 9 \\
\hline \multirow[t]{3}{*}{$\begin{array}{l}\text { Cuerpo } \\
\text { Humano }\end{array}$} & $\begin{array}{l}\text { 3a. La LM como API atiende a la nutrición (función de los } \\
\text { seres vivos) }\end{array}$ & 41 & 32 & 1 & 1 \\
\hline & $\begin{array}{l}\text { 3b. La LM como API atiende a la relación (función de los } \\
\text { seres vivos) }\end{array}$ & 0 & 0 & 7 & 7 \\
\hline & $\begin{array}{l}\text { 4. Anatomía y fisiología de la LM ¿Cómo es y cómo } \\
\text { funciona una mama humana para producir leche? }\end{array}$ & 1 & 1 & 1 & 1 \\
\hline \multirow[t]{2}{*}{$\begin{array}{l}\text { Seres vivos: } \\
\text { Mamíferos }\end{array}$} & $\begin{array}{l}\text { 5. Los animales mamíferos maman leche de sus madres } \\
\text { tras nacer }\end{array}$ & 82 & 43 & 3 & 3 \\
\hline & $\begin{array}{l}\text { 6. Somos mamíferos, o sea, que tras nacer nos } \\
\text { alimentamos de las mamas de nuestras madres }\end{array}$ & 26 & 20 & 3 & 3 \\
\hline
\end{tabular}

${ }^{1}$ N.R.: Número de veces que aparece el ítem en los libros de texto; ${ }^{2}$ N.L.: Número de libros de texto que contienen referencias a ese ítem. El número total de libros contabilizados es 75 .

Al comparar este dato con la presencia de contenidos afirmando explícitamente que el ser humano pertenece a esta clase (ítem 6), la información disminuye a una tercera parte. El ítem 6 aparece 26 veces en 20 libros distintos, por lo que es pobre la mención de que la forma de API específica en los seres humanos es la leche materna. En 3 casos se menciona la API con leche de fórmula como opción igual a la LM, propiciando la idea de inocuidad de su uso.

En cuanto a la categoría del cuerpo humano, para el ítem 3.a se han encontrado 41 referencias, en 32 manuales, asimilables al contenido escolar deseable, puesto que se menciona la LM como forma de alimentación, de modo que se relaciona con la función de nutrición. Sin embargo, la función de relación no se incluye como contenido relacionado con la API. No hay referencias al contenido escolar deseable, mientras que encontramos 7 manuales que introducen conocimiento no deseable respecto a este contenido, al mostrar imágenes de bebés alimentándose solos, sin presencia de figura materna ni otro adulto con el que relacionarse. En los temas sobre reproducción, donde sería oportuno tratar el funcionamiento de la mama para producir leche (ítem 4), solo se mencionan, en un caso, los genitales internos, omitiendo información acerca de estructuras relacionadas con la API con LM, tales como la glándula mamaria, algún tipo de referencia a la glándula hipófisis en el hipotálamo y su interacción hormonal. Únicamente en un solo libro de texto se menciona que «al final del embarazo las mamas se preparan para producir la leche $[. .]$.$» .$

Observamos que no se hace referencia a las indicaciones en cuanto a duración recomendada 
del periodo de alimentación con leche materna en la API (ítem 2), solo en un manual se afirma: «Al principio, se alimentan sólo de leche que maman de la madre. Poco a poco les salen los dientes y entonces alternan la leche con alimentos que tomarán cuando sean adultos». Y las 10 referencias a la duración indican, en 9 de los libros analizados, periodos inferiores al recomendado por las autoridades sanitarias.

Otro dato a resaltar es la ausencia de referencias al efecto protector de la leche materna frente a problemas de salud (item 1), mientras que son numerosas las menciones a la alimentación con leche artificial como alimento alternativo equivalente a la leche materna (con 20 referencias en 18 de los manuales consultados).

Estas carencias observadas no mejoran sustancialmente con la implantación de la LOMCE. El análisis comparativo de los datos basados en el número de referencias (Figura 1) y en el número de manuales (Figura 2) denota que existen pocas diferencias. En las gráficas se compara la presencia de contenidos que se ajustan al conocimiento escolar deseable, en color azul (Figura 1) y morado (Figura 2) y los contenidos relativos al conocimiento no deseable, en color amarillo en la primera figura y verde en la segunda.

Al comparar las publicaciones según las dos leyes, en lo relativo a contenidos que podrían introducir obstáculos para el aprendizaje, encontramos que en los textos más modernos, por una parte, aumenta la cantidad de referencias al contenido escolar deseable del ítem 5. Pero, por otra parte, hay un incremento de mensajes que introducen ideas alejadas del conocimiento escolar deseable, por ejemplo, con imágenes de animales mamíferos en su hábitat siendo alimentados con biberón.

Para el ítem 2 aumenta el número de referencias y manuales que presentan contenidos no deseables con respecto al periodo recomendado de alimentación del lactante.

En los ítems 1 (protección de la LM ante enfermedades frente a riesgos de la alimentación artificial), 3.b (función de relación en la API) y 6 (ser humano como mamífero) observamos una disminución del porcentaje de referencias a contenidos no deseables. Esta puede estar asociada a la menor cantidad de manuales publicados bajo la LOMCE con presencia de estos contenidos.

En cambio, para el ítem 3.a observamos una desaparición de mensajes con contenidos no deseables, en relación a la función de nutrición de la leche materna como API. Y, finalmente, ocurre lo contrario en el caso del ítem 4, en el que los contenidos en libros LOMCE referentes a anatomía y fisiología de la LM pueden introducir conocimiento no deseable. 


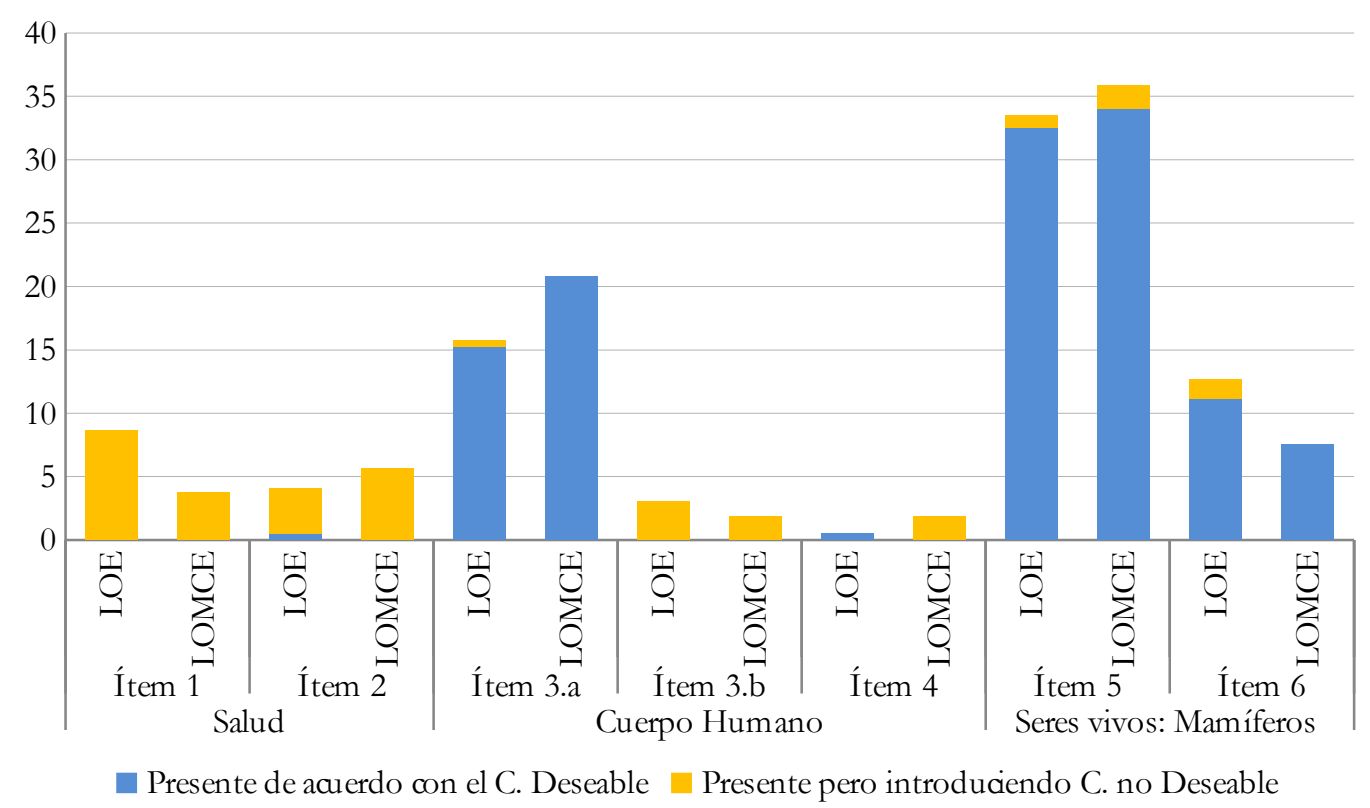

Figura 1. Porcentaje del número de referencias a cada ítem en libros de texto (LOE, LOMCE), respecto al total.

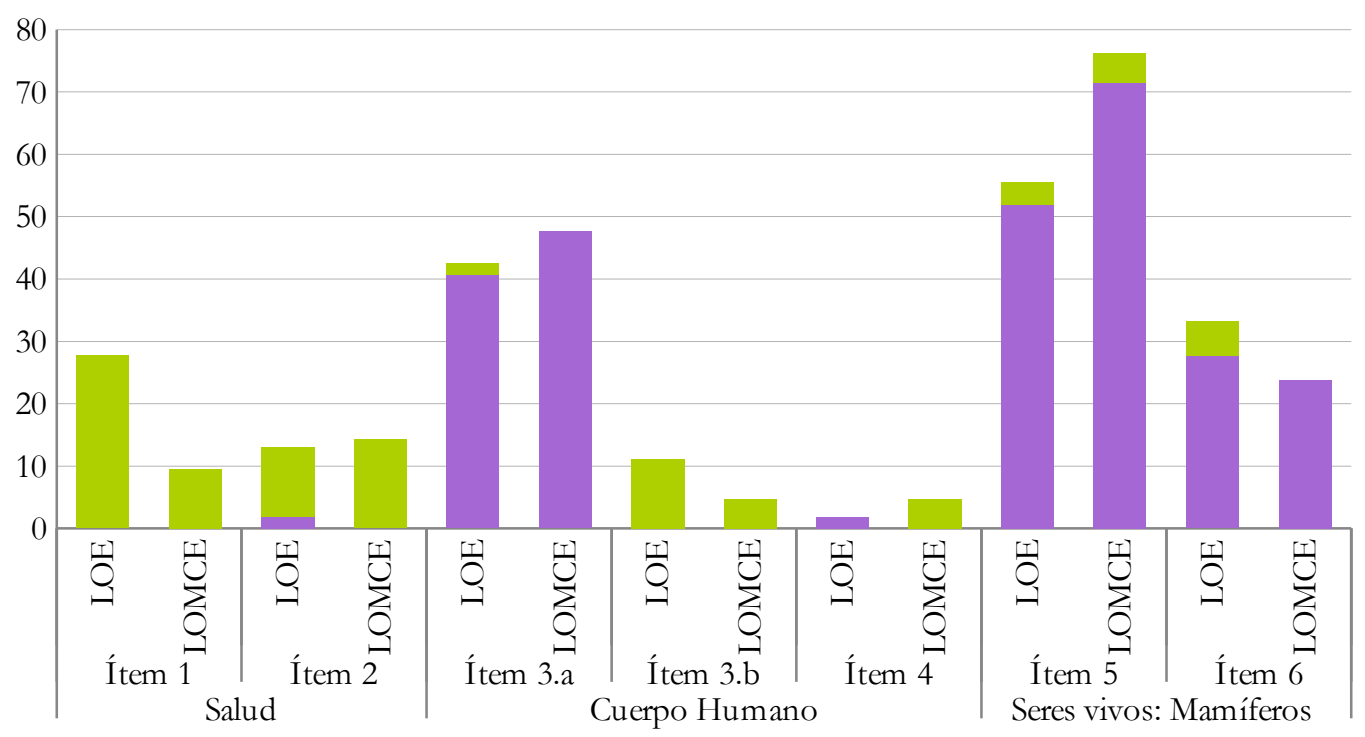

Presente de acuerdo con el C. Deseable $\square$ Presente pero introduciendo C. no Deseable

Figura 2. Porcentaje del número de libros de texto que contienen referencias a cada ítem, teniendo en cuenta que el número total de libros contabilizados es 54 (LOE) y 21 (LOMCE).

\section{Discusión y conclusiones}

Los resultados obtenidos vienen a complementar los anteriores estudios. Partiendo de la escasa presencia, en general, de contenidos relativos a la API, coincidimos con lo hallado por Pegenaute (2007) en España y por Galvão y Silva (2013) en Brasil, en que es mayoritaria la caracterización de mamífero como animal que se alimenta de la leche de su madre tras nacer, así como en la ausencia de referencias a la anatomía y fisiología de la LM en relación a la API (Hervás 2014; Torres 2019). 
Sin embargo, con respecto a los trabajos mencionados, aunque se mantienen por encima de lo hallado en Portugal (Galvão y Silva 2011), en este estudio descienden las referencias al ser humano como mamífero. Afirmación que es básica para que las personas con hijos recién nacidos no duden en la capacidad del cuerpo femenino para amamantar (Paricio et al. 1999).

Asimismo las referencias a la relación de la LM con las funciones vitales y a su efecto saludable frente a la API con leche de fórmula son inferiores a lo registrado en anteriores estudios (Pegenaute 2007), así como la presencia de recomendaciones oficiales sobre el periodo de LM en la API (Galvão y Silva 2013).

Otra de las coincidencias se da en la presencia de mensajes que contribuyen a mantener la concepción inadecuada de que la API con leche materna y con leche artificial es equivalente. Las referencias al efecto saludable de la API con LM son escasas y predomina la tendencia a considerar la API con leche artificial (Galvão y Silva 2011, 2013).

Coincidimos con los trabajos citados (Galvão y Silva 2011, 2013) en que se están perdiendo oportunidades para promover en la escuela uno de los pilares de la salud pública, la alimentación con leche materna en la primera etapa de la vida (Martínez-Roche 2000; RCPCH 2017; Stuart-Macadam y Dettwyler 1995).

La actualización de los libros de texto con la reforma de la legislación no ha supuesto una mejora en el tratamiento de las cuestiones sobre cuerpo humano y salud, en lo referente a la API y la LM. Eso mismo ha ocurrido en otros ámbitos como la incorporación de la perspectiva Ciencia, Tecnología, Sociedad y Ambiente (Borges, Pires y Delgado-Iglesias 2010).

Retomando las preguntas que nos planteamos, en los libros de texto para la Educación Primaria en Andalucía se percibe una baja presencia de contenidos relacionados con la alimentación específica para la primera infancia en el ser humano. Encontramos también una extendida presencia de imágenes y mensajes poco pertinentes que obstaculizan el aprendizaje (Peláez, Rodriguez y Occelli 2010). Además, encontramos cierta incoherencia en cuanto a la presencia de contenidos adecuados combinada con contenidos no deseables.

En relación a la pregunta $i$, los resultados obtenidos en este análisis indican que no se relaciona la API mediante LM con la salud, ni del hijo ni de la madre. Es más, los contenidos presentes transmiten la falsa percepción de que la API con leche artificial es equivalente a la LM y que la primera es inocua. De manera parecida, en cuanto a la pregunta ii los valores obtenidos nos permiten constatar que no se aporta información sobre las estructuras del cuerpo humano y su funcionamiento para llevar a cabo una API saludable mediante LM.

Como excepción, la situación para la pregunta iii nos muestra que, efectivamente, se establece una relación entre animales mamíferos con el hecho de tomar leche materna tras nacer. A pesar de ser el contenido más representado, la presencia de dichos contenidos se mantiene solo en poco más de la mitad de los manuales consultados. En cambio, para la pregunta $i v$, los valores descienden más de lo que podríamos esperar. ¡Encontramos menos de la mitad de referencias al ser humano como mamífero que las referidas a animales!

En lo relativo a la pregunta $v$, en primer lugar, con respecto a la relación de la API con la salud, encontramos que apenas se muestran imágenes de bebés mamando de su madre. Por el contrario, predominan ilustraciones que eluden la alimentación con LM como inherente característica de la especie humana como mamífero. Esto constituye un obstáculo para que los escolares obtengan una idea adecuada sobre la forma de API más saludable. Un efecto similar producen los mensajes referentes a la duración recomendada de este tipo de alimentación.

En segundo lugar, en lo referente a las funciones vitales, se puede considerar que los libros de texto relacionan la LM con la función de nutrición. Sin embargo, la implicación de la función 
de relación es obviada o se aporta información inadecuada (bebé comiendo solo). Por otro lado, la poca información que se aporta acerca de la anatomía y funcionamiento del cuerpo humano en relación a la LM puede promover concepciones alternativas en cuanto a la capacidad del cuerpo femenino para participar en la API. En tercer lugar, resulta preocupante la presencia de contenidos no deseables sobre los mamíferos, aunque sea menor que en otros casos (como absurdas imágenes de animales tomando biberón en su hábitat).

Para la última pregunta, $v i$, (diferencias entre la anterior LOE y la actual LOMCE) en algunos aspectos se mejora y en otros se empeora. En concreto, se ha mejorado el tratamiento de la función de nutrición relacionada con la API y la caracterización de mamíferos como animales que maman. Por el contrario, se reduce o desaparece información sobre el periodo de la API, contenidos sobre fisiología y anatomía y la referencia al ser humano como mamífero. Con respecto a la presencia de mensajes que pueden promover conocimiento no deseable, se han hallado valores similares. Como excepción hay un descenso en la presencia de mensajes sobre los efectos del tipo de API sobre la salud, y esto puede ser debido al menor número de referencias a la temática. Si bien, debemos considerar con precaución estas conclusiones, ya que el número de manuales LOMCE analizados fue menor.

En general, podemos decir que estamos ante un sesgo de información, por exclusión (Torres 2019), para los contenidos relacionados con la educación para una API saludable. Encontrando, por el contrario, presencia de informaciones y elementos que favorecen los errores conceptuales sobre la LM.

\section{Limitaciones del estudio y perspectivas futuras}

Ya avanzábamos que la línea de investigación sobre la temática de la alimentación en la primera infancia está poco desarrollada. Aunque en este trabajo se ha pretendido contribuir un poco a su avance, queda por analizar y comparar qué ocurre en otros países externos a Iberoamérica, por ejemplo en países anglosajones o en países del norte de Europa donde la maternidad está más integrada y las políticas sociales facilitan la crianza de los hijos.

Nos preguntamos también cómo será el tratamiento de la API en textos en otros niveles educativos, donde la influencia e importancia de una buena educación en LM puede estar todavía más directamente relacionada con los contenidos.

Además, con el objeto de mejorar el instrumento de análisis de libros de texto, se añadiría la búsqueda de contenidos de tipo procedimental, por ejemplo, cómo se da el pecho adecuadamente (Pegenaute 2007), y actitudinal como razones para optar por la API con LM (Galvão y Silva 2011).

\section{Referencias bibliográficas}

Aguayo J., Gómez A., Hernández M.T., Lasarte J.J., Lozano M.J., Pallás C.R. (2008) Manual de lactancia materna: de la teoría a la práctica. Madrid: Editorial médica panamericana.

Angell C., Alexander J., Hunt J.A. (2011) How are babies fed? A pilot study exploring primary school children's perceptions of infant feeding. Birth 38(4), 346-53. https://doi.org/10.1111/j.1523-536X.2011.00484.x

Azcárate P., Serradó A. (2006) Tendencias didácticas en los libros de texto de matemáticas para la ESO. Revista de Educación 340, 341-378.

Banet E., Núñez F. (1991) Estudio de los alimentos: Plan de actuación basado en una secuencia constructivista del aprendizaje. Investigación en la Escuela 13, 31-58.

Banet E., Buíza C., Carmen L. M. del, Febrel M., Ferrer J.M., Fuentes M., Gallego J., Gavidia V., Gómez C., Granizo C., Núñez F., Muñoz A., Quer J., Rodes M.J., Ríos I., Rambla 
A., Sala M.A., Yus R., Tro Ll. (2004) Educación para la salud: la alimentación. Barcelona: Graó.

Basulto J. (2013) Se me hace bola: Cuando no comen como queremos que coman. Barcelona: Debolsillo.

Becerra F., Peña D.C., Puentes, V.A. Rodríguez, D.E. (2009) Breastfeeding: A review of its evolution through time. The case of some indigenous communities in Colombia. Revista Facultad de Medicina 57(3), 246-257.

Berry N.J., Gribble K.D. (2008) Breast is no longer best: promoting normal infant feeding. Maternal \& Child Nutrition 4(1), 74-9. https://doi.org/10.1111/j.17408709.2007.00100.x

BOE (2014a) Real Decreto 165/2014, de 14 de marzo, por el que se modifica el Real Decreto $867 / 2008$, de 23 de mayo, por el que se aprueba la reglamentación técnico-sanitaria específica de los preparados para lactantes y de los preparados de continuación. Boletín Oficial del Estado, núm. 131, de 30 de mayo de 2008, pp. 25121 a 25137.

BOE (2014b) Real Decreto 126/2014, de 28 de febrero, por el que se establece el currículo básico de la Educación Primaria. Boletín Oficial del Estado, núm. 52, de 1 de marzo de 2014, pp. 19349 a 19420.

Borges I., Pires D., \& Delgado-Iglesias J. (2016) Las relaciones entre Ciencia, Tecnología, Sociedad y Ambiente, en los libros de texto de Educación Primaria: Un estudio comparativo entre Portugal y España, antes de las últimas reformas educativas. Revista Eureka sobre Enseñanza y Divulgación de las Ciencias 14(1), 54-68. http://dx.doi.org/10.25267/Rev_Eureka_ensen_divulg_cienc.2017.v14.11.05

Bottaro S.M., Giugliani E.R.J. (2008) Estudo exploratório sobre aleitamento materno entre escolares de quinta série do Ensino Fundamental. Cadernos de Saúde Pública 24(7), 1599608. https://doi.org/10.1590/S0102-311X2008000700015

Bottaro S.M., Giugliani E.R.J. (2009) Effectiveness of an Intervention to Improve Breastfeeding Knowledge and Attitudes Among Fifth-grade Children in Brazil. Journal of Human Lactacion 25(3),325-332. https:/ / doi.org/10.1177/0890334409337248

Brahm P., Valdés V. (2017) Beneficios de la lactancia materna y riesgos de no amamantar. Revista chilena de pediatría 88(1), 07-14. https://doi.org/10.4067/S037041062017000100001

Campanario J.M. (2003) De la necesidad, virtud: cómo aprovechar los errores y las imprecisiones de los libros de texto para enseñar física Enseñanza de las Ciencias 21(1), 161-172.

Cañal P., Criado A. (2002) ¿Incide la investigación en didáctica de las ciencias en el contenido de los libros de texto escolares?: El caso de la nutrición de las plantas. Alambique: Didáctica de las Ciencias Experimentales (34), 56-65.

Cherrett I., Flores G.A., Dárdano C., López E.V., Ordóñez A.L., Múñoz M.M., Suazo L.D., Bardales H.A. (2012) Plan de Capacitación para la Enseñanza de la Alimentación y Nutrición. Dirigido a docentes de primero y segundo ciclo. Honduras: FAO. Secretaría de Educación.

Clark A., Anderson J., Adams E., Baker S. (2008) Assessing the Knowledge, Attitudes, Behaviors and Training Needs Related to Infant Feeding, Specifically Breastfeeding, of Child Care Providers. Maternal and Child Health Journal 12 (1), 128-135. https://doi.org/10.1007/s10995-007-0221-4

Consejería de Salud. Junta de Andalucía. España. (2006) Plan Integral de la Obesidad Infantil de 
Andalucía 2007-2012. Sevilla: Junta de Andalucía.

Costa M.M., Diniz-Santos D.R., Santana J.S., Silva L.R. (2006) The impact of an educational intervention on breastfeeding. Health education 106(4), 309-314. https://doi.org/10.1108/09654280610673481

Costa M.M.S.M., Silva L.R. (2008) Programas de incentivo ao aleitamento materno. Incentivo ao aleitamento materno para crianças em idade escolar. En Issler H. (Ed.) O aleitamento materno no contexto atual: políticas, prática e bases cientificas (pp.121-129). São Paulo: Sarvier.

de Toledo O.R., Honório-França AC., Hadley C., Lindstrom D., Belachew T., Tessema F. (2007) Ethiopian adolescents' attitudes and expectations deviate from current infant and young child feeding recommendations. Journal of adolescent health 01(15), 1-7.

De Vega B.G. (12 de julio de 2018) Teta o biberón: la batalla que divide España. El Mundo.

Del Carmen L.M. (2010) La alimentación: algo más que ingerir alimentos. Alambique 66, 66-72.

Del Cid R., Rivas M. (1989) La alimentación humana en los libros de texto de Ciencias de la Naturaleza de EGB. II Encuentro Nacional sobre El Libro Escolar (1989), 166-173.

Díaz-Méndez C. (2012) El tratamiento institucional de la alimentación : un análisis sobre la intervención contra la obesidad. Papers: revista de sociologia 97 (2), 371-384. https://doi.org/10.5565/rev/papers/v97n2.120

Duncan J., Bartle C. (2014) Normalising the Breast: Early Childhood Services Battling the Bottle and the Breast. Contemporary Issues in Early Childhood 15(1), 18-28. https://doi.org/10.2304/ciec.2014.15.1.18

Fujimori M., Morais T.C., França E.C. (2008) The attitudes of primary school children to breastfeeding and the effect of health education lectures. Jornal de Pediatria 84(3), 22431. https://doi.org/10.2223/JPED.1791

Galvão D.M.P.G., Silva I.A. da. (2011) A amamentação nos manuais escolares de estudo do meio do $1^{\mathrm{o}}$ ciclo do ensino básico. Revista de Enfermagem Referência 3 (4), 7-16. https://doi.org/10.12707/RIII1030

Galvão D.M.P.G., Silva I.A. da. (2013) Abordagem da amamentação nos primeiros anos do ensino fundamental / The approach to breastfeeding in the first years of elementary school / Abordaje de la lactancia en los primeros años de la enseñanza primaria. Revista Da Escola De Enfermagem Da USP (2), 477. https://doi.org/10.1590/S008062342013000200029

García-Barros S., Martínez-Losada C. (2003) Análisis del práctico en textos escolares de primaria y secundaria. Enseñanza de las Ciencias No Extra 5-16.

Gavira-López F., Gavira-Segovia I., Jiménez-Moya A., López-Pérez T., Suárez-Bárcena A.M. (2013). Lactancia Materna en el Entorno Educativo. Servicio Andaluz de Salud. Consejería de Igualdad, Salud y Políticas Sociales.

Gil-García E., Conti-Cuesta F., Pinzón-Pulido S.A., Prieto-Rodríguez M.A., Solas-Gaspar O., Cruz-Piqueras M. (2002) El análisis de texto asistido por ordenador en la investigación cualitativa. Index de Enfermería 11(36-37), 24-28. 
Gómes M.R. (2012) Conocimiento empirico, saberes escolares e identidades gastronómicas. La transmisión de la cultura alimentaria en contextos locales (Tesis doctoral) Universidad de Sevilla.

González F. (2015) Didáctica de las Ciencias para Educación Primaria II. Ciencias de la vida. Madrid: Ediciones Pirámide.

Hernández M.T., Aguayo J., Gómez A. (2008) Toma de decisiones informadas sobre la alimentación del lactante. En Asociación Española de Pediatría (Ed.) Manual de Lactancia Materna. De la teoría a la práctica (pp. 41-46). Madrid: Editorial Médica Panamericana.

Hervás I. (2014) Conocimiento sobre Lactancia Materna en el alumnado de primer curso de Auxiliares de Enfermería. Valoración de la eficacia de un Taller teórico-práctico para corregir preconceptos erróneos y mejorar el nivel de conocimientos. (Trabajo final de máster). Universidad Internacional de La Rioja.

Illescas-Navarro M., Cruz-Guzmán M,. Criado A.M. (2018) ¿Se debería tratar la lactancia materna en las clases de ciencia en Educación Primaria? Preguntamos al futuro profesorado. En IV Simposio de Enseñanza de las Ciencias. Vigo: Universidad de Vigo.

Jiménez-Moya A.I. (2015) Lactancia materna en el entorno educativo. En IX Jornadas de salud perinatal y reproductiva. Santiago de Compostela: Servicio Gallego de Salud.

Jiménez-Moya A.I. (2016) Educación sanitaria y su influencia en la lactancia materna en el Campo de Gibraltar (Tesis doctoral). Universidad de Málaga.

Laredo-Ortiz S. (2005) Proyecto para introducir la lactancia materna en los centros educativos. En III Congreso Español de Lactancia Materna (pp.57-59). Santander: Editorial Ergon.

Martín del Pozo R. (coord.) (2013) Las ideas "cientificas" de los alumnos y alumnas de primaria: tareas, dibujos y textos. Madrid: Universidad Complutense.

Martínez P. (2015) Lactancia Materna. Lo que hay que oir: Compendio de mitos y situaciones absurdas alrededor de la lactancia materna. Columbia: Pilar Martínez Álvarez.

Martínez-Roche M.E. (2000) Debe fomentarse la lactancia natural desde la Educación Primaria. Revista ROL de enfermería 23(6), 433.

Martins I.P., Brigas M.A. (2005) Libros de texto de Química y aprendizaje de los alumnos: pensamiento y prácticas del profesorado. Tarbiya. Revista de Investigación e Innovación Educativa 36, 149-165.

OMS. Organización Mundial de la Salud. Regional Office for Europe. (2000a). Healthy eating for young people in Europe: a school-based nutrition education guide. Copenhagen: WHO Regional Office for Europe.

OMS. Organización Mundial de la Salud (2000b). Improving Health through Schools: National and International Strategies. Geneva: WHO Information Series on School Health.

OMS. Organización Mundial de la Salud (2002). Estrategia mundial para la alimentación del lactante y del niño pequeño. Informe de la Secretaría. Ginebra: 55 a Asamblea Mundial de la Salud.

OMS. Organización Mundial para la Salud (2009) Baby-friendly hospital initiative: revised, updated and expanded for integrated care. Section 2.Strengthening and sustaining the baby-friendly hospital initiative: a course for decision-makers. Ginebra: WHO Guidelines Approved by the Guidelines Review Committee.

OMS. Organización Mundial para la Salud (2011) La lactancia materna exclusiva durante los primeros 6 meses es lo mejor para todos los niños. (En línea) WHO Guidelines Approved by 
the Guidelines Review Committee.

Padilla M.T. (2002) Técnicas e instrumentos para el diagnóstico y la evaluación educativa. Madrid: CCS.

Padró A. (2017) Somos la leche: Dudas, consejos y falsos mitos sobre la lactancia (Embarazo, bebé y niño). Barcelona: Grijalbo.

Palacios R. (2017) Aprendizaje de propiedades elementales de la materia: volumen, masa y densidad, en estudiantes de ESO (Tesis doctoral) Universidad de Sevilla, Sevilla.

Palacios-Díaz R., Criado A.M. (2017) Lo que no dicen los libros españoles de texto de educación secundaria obligatoria sobre la masa, el volumen y la densidad. Enseñanza de las Ciencias 35 (2), 51-70.

Pallás C.R., Baeza C. (2006) El médico de familia y la formación en lactancia materna. Atención Primaria 38(2), 67-68. https://doi.org/10.1157/13090431

Paricio J., Santos L., Fernández A., Martí E., Bernat A., Ferriol M. (1999) Lactancia materna: conocimientos, actitudes y ambigüedad sociocultural. Atención primaria 24 (6), 337-343.

Pegenaute E. (2007) La lactancia materna en los libros de texto de ciclo medio y superior de Educación Primaria en Cataluña. En Proceedings of the 4th Congreso Fedalma 21-22.

Peláez C., Rodríguez J.M., Occelli M. (2010) Análisis del concepto de reproducción en libros de texto para el primer ciclo de la escuela secundaria (EGB 3) Revista de educación en biología 13(2), 7-15.

Perales F.J. (2006) Uso (y abuso) de la imagen en la enseñanza de las ciencias. Enseñanza de las Ciencias 24(1), 13-30.

Perales F.J., Vílchez J.M. (2012) Libros de texto: ni contigo ni sin ti tienen mis males remedio. Alambique: didáctica de las ciencias experimentales 18(70), 75-82.

Pérez de Eulate, L., Llorente E. (2015) ¿Qué enseñar en la educación obligatoria acerca de la alimentación y la actividad física? Un estudio con expertos. Enseñanza de las Ciencias 33(1), 85-100.

Porta L., Silva M. (2003) La investigación cualitativa: El Análisis de Contenido en la investigación educativa. Red Nacional Argentina de Documentación e Información Educativa 118.

Pozuelos F.J., Morcillo V., Travé G.H. (2016) La alimentación en los libros de texto. En P. Cañal, G. Travé, F.J. Pozuelos, A.M. Criado y A. García-Carmona (Coord.) La enseñanza sobre el medio natural y social: investigaciones y experiencias (pp. 149-173) Sevilla: Díada Editora.

Rivadulla-López J.C., García-Barros S., Martínez-Losada C. (2016) Historia de la Ciencia e ideas de los alumnos como referentes para seleccionar contenidos sobre nutrición. Revista Eureka sobre Enseñanza y Divulgación de las Ciencias 13(1), 53-66. https://doi.org/10.25267/Rev_Eureka_ensen_divulg_cienc.2016.v13.i1.05

Rivadulla-López J.C., Fuentes M.J., García-Barros, S. (2017) La evaluación de la alimentación humana según maestros en formación de España/Portugal. Revista de estudios e investigación en psicología y educación (6), 180-185. https://doi.org/10.17979/reipe.2017.0.06.2443

Rodrigo M., Ejeda J. (2009) Concepciones erróneas sobre alimentación en futuros profesores. Construcción de conocimiento pedagógico. Teoría de la Educación. Revista Interuniversitaria 20. https://doi.org/10.14201/ted.991 
Rodríguez F.P., De las Heras M.A., Romero R., Cañal P. (2014) El conocimiento escolar sobre los animales y las plantas en primaria: Un análisis del contenido específico en los libros de texto. Revista Electrónica de Enseñanza de las Ciencias 13(1), 97-114.

Rodríguez-Moreno J., de Pro-Bueno A., Molina-Jaén M. D. (2018) Opinión de los docentes sobre el tratamiento de las competencias en los libros de texto de Ciencias de la Naturaleza en Educación Primaria. Revista Eureka sobre Enseñanza y Divulgación de las Ciencias 15(3), 3102. https://doi.org/10.25267/Rev_Eureka_ensen_divulg_cienc.2018.v15.i3.3102

RCPCH. Royal College of Paediatrics and Child Health (2017) Position Statement: breastfeeding in the UK: August 2017. United Kingdom.

Stuart-Macadam P., Dettwyler K. (1995) Breastfeeding Biocultural Perspectives. New York: Aldine De Gruyter.

Stuebe A. (2009) The risks of not breastfeeding for mothers and infants. Reviews in obstetrics and gynecology 2(4), 222.

Terrengui L.C.S. (2003) Evaluation of an Educational Program on Breastfeeding Applied to Elementary School Students (Tesis doctoral). São Paulo: Universidade de Santo Amaro.

Torres J. (2019) ¿Qué esconden los libros de texto? Análisis crítico de su contenido. Conferencia Proyecto de Innovación Trabajo por proyectos en la formación inicial del profesorado. III Plan propio de docencia. Universidad de Sevilla.

Torres M., Marrero M., Navarro C., Gavidia V. (2018) ¿Cómo abordan los textos de Educación Primaria la competencia en alimentación y actividad física? Revista Eureka sobre Enseñanza y Divulgación de las Ciencias 15(1), 1103. https://doi.org/10.25267/Rev_Eureka_ensen_divulg_cienc.2018.v15.11.1103

Vallone F. (2009) Pequeños grandes clientes: la publicidad de sucedáneos de la leche materna en dos revistas pediátricas de Argentina entre 1977 y 2006. Salud colectiva 5(1), 87-105. https://doi.org/10.18294/sc.2009.232

WABA. World Alliance for Breastfeeding Action (1999) Lactancia materna: educar para la vida [En línea]. En World Breastfeeding Week. 


\section{Anexos}

Anexo I. Libros de texto analizados: Editorial, curso y año de edición. En la última columna se detalla el número total de ejemplares para cada nivel.

\begin{tabular}{|c|c|c|c|c|c|c|c|c|}
\hline $\begin{array}{l}\text { Nivel\E } \\
\text { ditor }\end{array}$ & Santillana & Anaya & Bruño & $\begin{array}{l}\text { Luis } \\
\text { Vives }\end{array}$ & Edebé & SM & $\begin{array}{l}\text { Vicens } \\
\text { Vives } \\
\end{array}$ & Total (75) \\
\hline $1^{\circ}$ & $\begin{array}{l}2000 \\
2008 \\
2014 \\
2015\end{array}$ & $\begin{array}{l}2007 \\
2015 a \\
2015 b\end{array}$ & 2008 & $\begin{array}{l}2004 \\
2007 \\
2008\end{array}$ & 2014 & 2014 & $\varnothing$ & 13 \\
\hline $2^{\circ}$ & $\begin{array}{l}2000 \\
2015\end{array}$ & $\begin{array}{l}2005 \\
2007 \\
2008 \\
2015\end{array}$ & 2008 & 2004 & $\begin{array}{l}2004 \\
2015\end{array}$ & 2015 & 2015 & 12 \\
\hline $3^{\circ}$ & $\begin{array}{l}2005 \\
2008 \mathrm{a} \\
2008 \mathrm{~b}\end{array}$ & $\begin{array}{l}2004 \\
2005 \\
2008 \mathrm{a} \\
2008 \mathrm{~b} \\
2015\end{array}$ & 2008 & $\begin{array}{l}2008 \mathrm{a} \\
2008 \mathrm{~b} \\
2014\end{array}$ & $\begin{array}{l}2008 \\
2015\end{array}$ & $\begin{array}{l}2008 \\
2014\end{array}$ & $\begin{array}{l}2008 \\
2015\end{array}$ & 18 \\
\hline $4^{\circ}$ & 2008 & $\begin{array}{l}1997 \\
2001 \\
2008 \\
2015\end{array}$ & 2008 & $\begin{array}{l}2008 \mathrm{a} \\
2008 \mathrm{~b}\end{array}$ & $\begin{array}{l}2011 \\
2015\end{array}$ & 2010 & $\begin{array}{l}1999 \\
2008\end{array}$ & 13 \\
\hline $5^{\circ}$ & $\varnothing$ & $\begin{array}{l}2002 \\
2009 \\
2015\end{array}$ & $\varnothing$ & $\begin{array}{l}2009 a \\
2009 b\end{array}$ & 2009 & $\begin{array}{l}2006 \\
2010\end{array}$ & 2009 & 9 \\
\hline $6^{\circ}$ & 2015 & $\begin{array}{l}2005 \\
2006 \\
2009 \\
2015\end{array}$ & $\varnothing$ & 2009 & 2009 & $\begin{array}{l}2006 \\
2009\end{array}$ & 2011 & 10 \\
\hline
\end{tabular}

